Supporting information

\title{
Enhancement of $\mathrm{NH}_{3}$ Production in
}

\section{Electrochemical $\mathrm{N}_{2}$ Reduction by the $\mathrm{Cu}-\mathrm{Rich}$ Inner Surfaces of Beveled CuAu Nanoboxes}

Biva Talukdar, ${ }^{\dagger, \#, \circ}$ Tung-Chun Kuo,${ }^{\ddagger}$ Brian T. Sneed, ${ }^{\|}$Lian-Ming Lyu,${ }^{\S}$ Hung-Min Lin, $,{ }^{\dagger}, \perp$ Yu-Chun Chuang, ${ }^{\mathbb{I l}} \mathrm{Mu}-\mathrm{Jeng} \mathrm{Cheng}^{*}{ }^{\ddagger}$ and Chun-Hong Kuo ${ }^{*} \dagger, \triangle$

${ }^{\dagger}$ Institute of Chemistry, Academia Sinica, Taipei 11529, Taiwan

"Sustainable Chemical Science and Technology, Taiwan International Graduate Program, Academia Sinica and National Yang Ming Chiao Tung University, Taipei 11529, Taiwan

${ }^{\circ}$ Department of Applied Chemistry, National Yang Ming Chiao Tung University, Hsinchu 30010, Taiwan

${ }^{\ddagger}$ Department of Chemistry, National Cheng Kung University, Tainan 70101, Taiwan

${ }^{\|}$Cabot Microelectronics, Aurora, Illinois 60504, United States

${ }^{\S}$ Department of Materials Science and Engineering, National Tsing Hua University, Hsinchu 30013, Taiwan

${ }^{\perp}$ Department of Chemistry, National Taiwan University, Taipei 10617, Taiwan

"National Synchrotron Radiation Research Center, Hsinchu 30076, Taiwan

${ }^{\Delta}$ Institute of Materials Science and Engineering, National Central University, Taoyuan 32001, Taiwan

\section{Contact information of corresponding authors}

*(M.-J. C.) E-mail: mjcheng@ mail.ncku.edu.tw

*(C.-H. K.) E-mail: chunhong@gate.sinica.edu.tw 


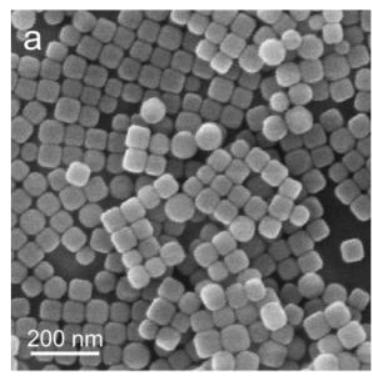

C

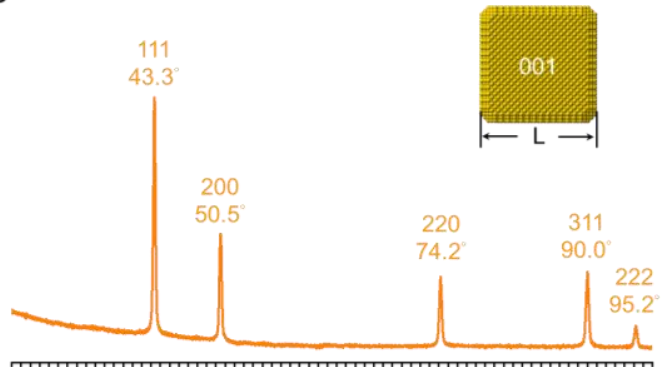

3035404550556065707580859095 $2 \theta$ (degree)
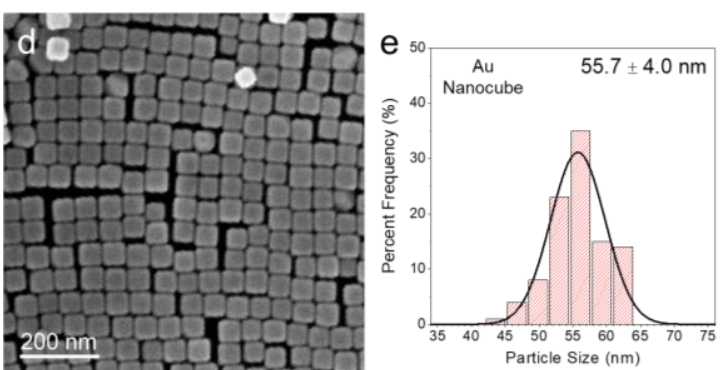

$f$

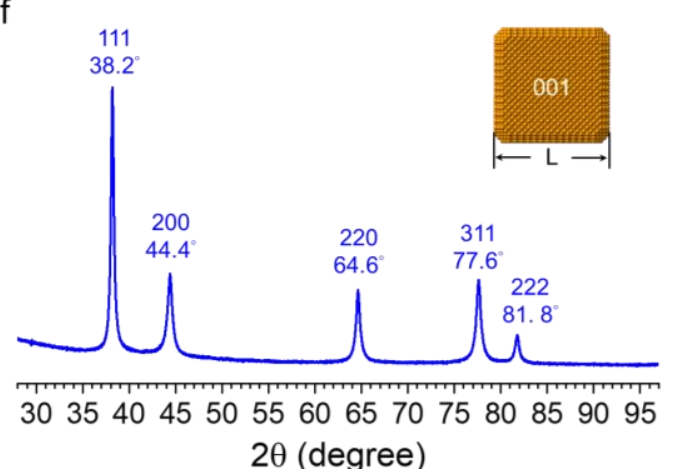

Figure S1. (a, d) SEM images, (b, e) size-distribution histograms, and (c, f) PXRD patterns of (a-c) $\mathrm{Cu}$, and (d-f) Au nanocubes.
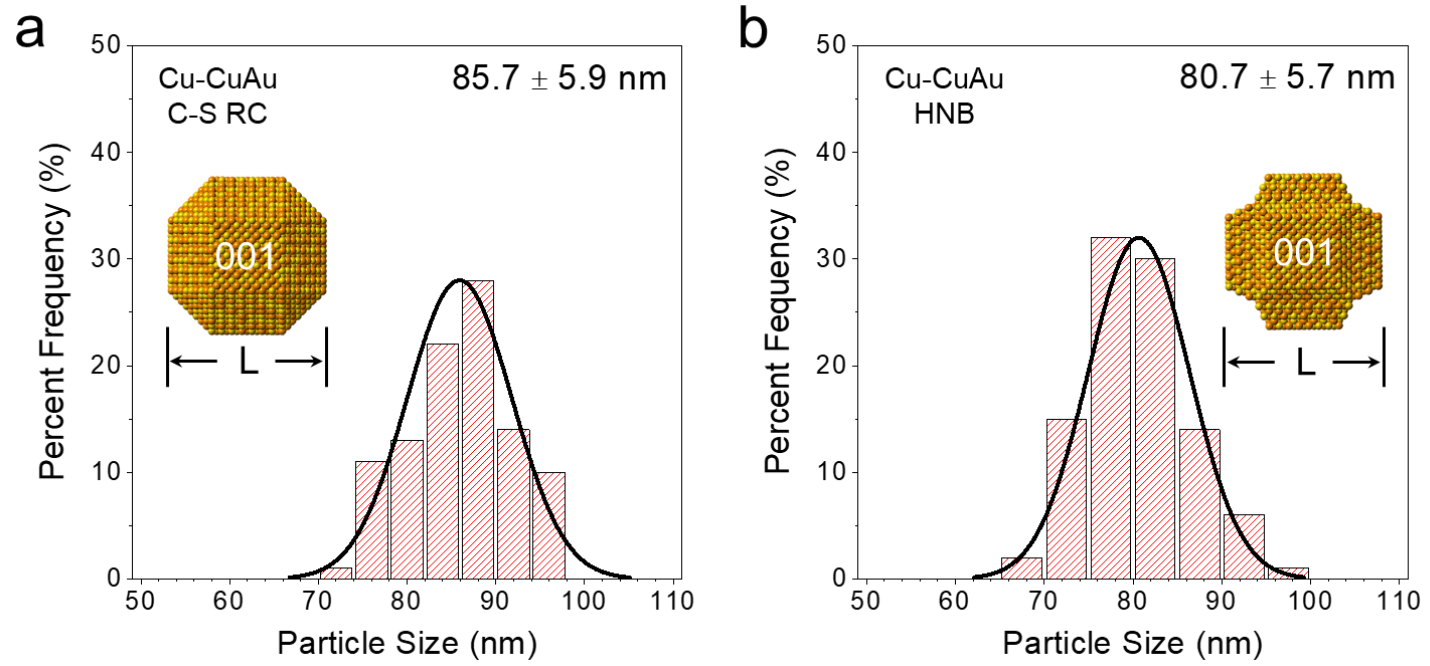

Figure S2. Size-distribution histograms of (a) rhombic cuboctahedral $\mathrm{Cu}-\mathrm{CuAu}$ core-shell nanocrystals, and (b) their corresponding hollow nanocages after removing $\mathrm{Cu}$ cores. 

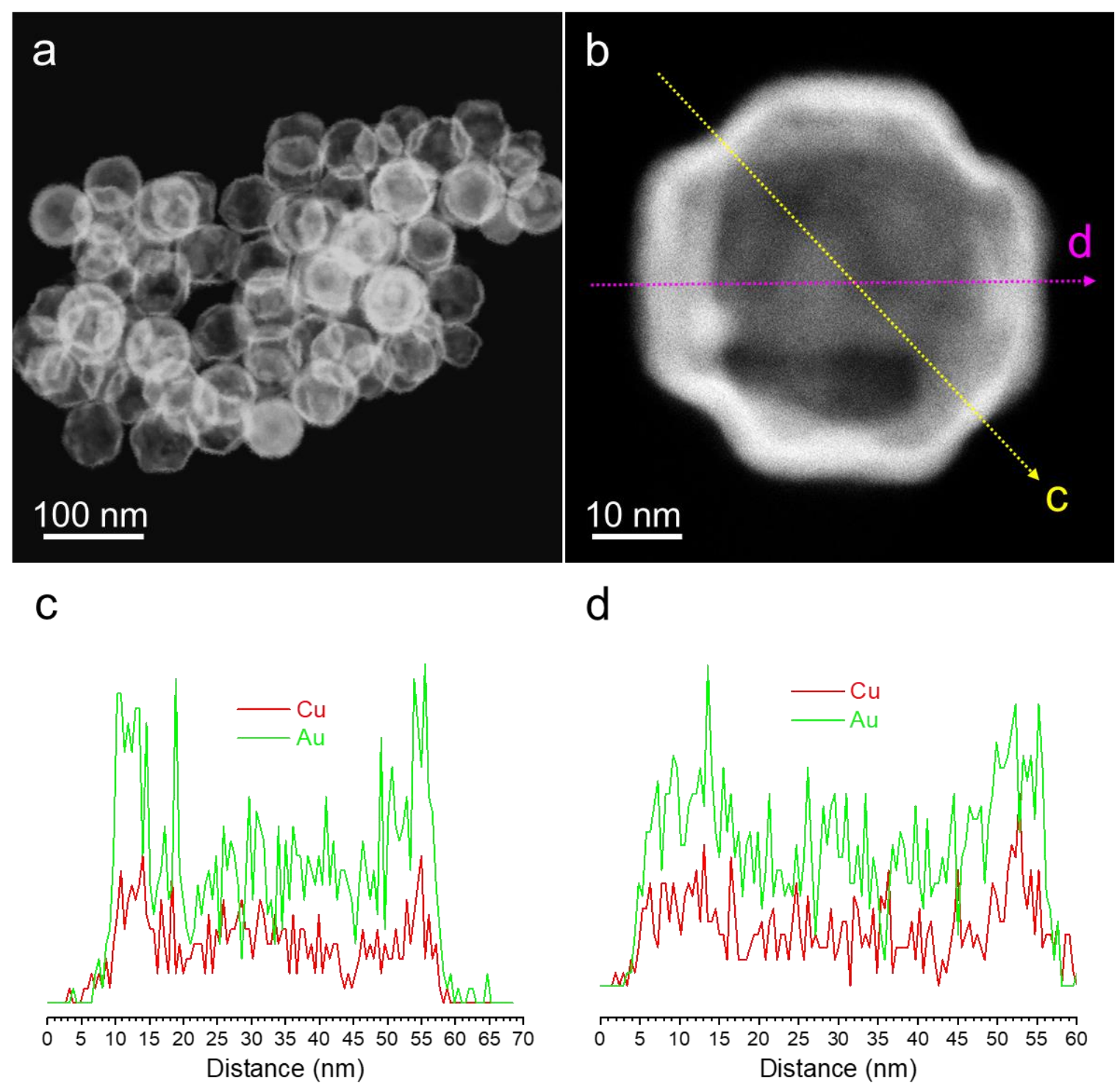

Figure S3. HAADF-STEM images of (a) multiple and (b) a single $\mathrm{CuAu}$ nanoboxes. The single nanocage is viewed along the [100] direction. (c, d) EDS line-scan profiles of the single nanobox along the yellow (c) and pink (d) cross sections. 


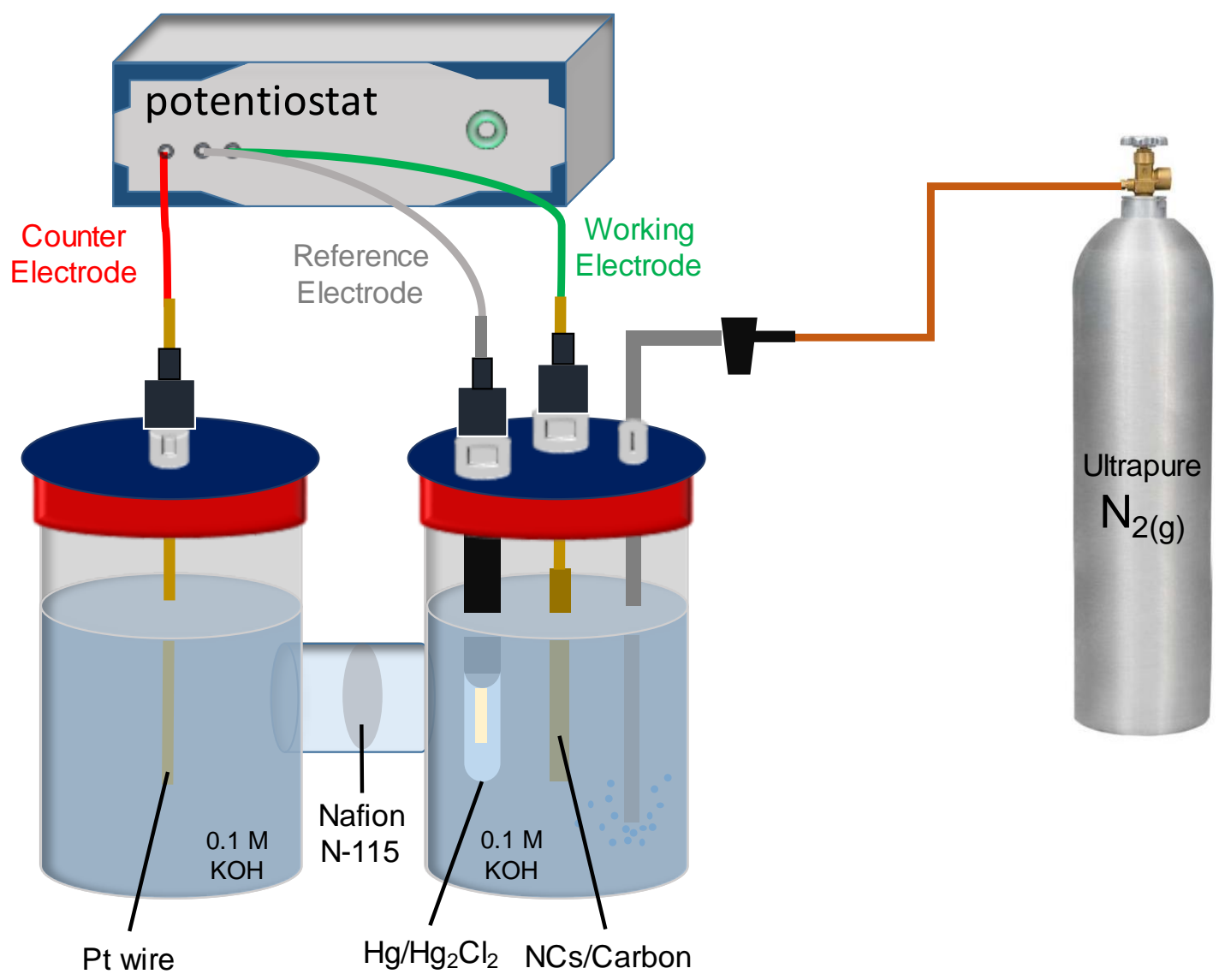

Figure S4. Schematic illustration for the setup of electrochemical $\mathrm{N}_{2}$ reduction reaction. 


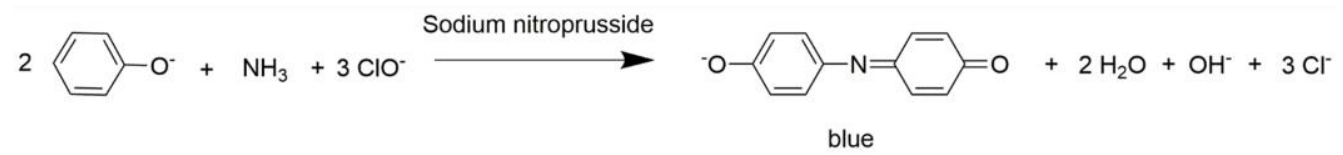

b

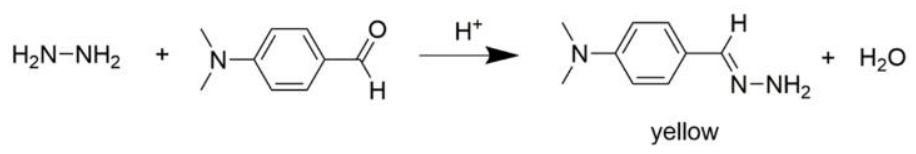

Figure S5. The condensation reactions for (a) indophenol blue method, and (b) Watt and Chrisp's Method.

a

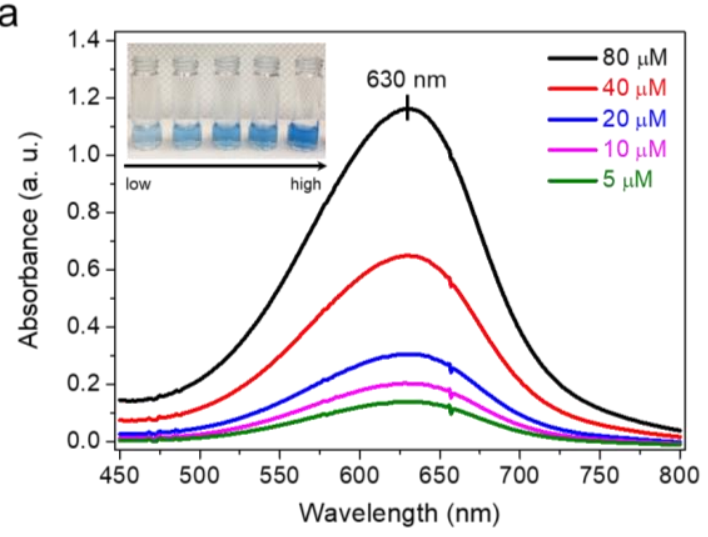

C

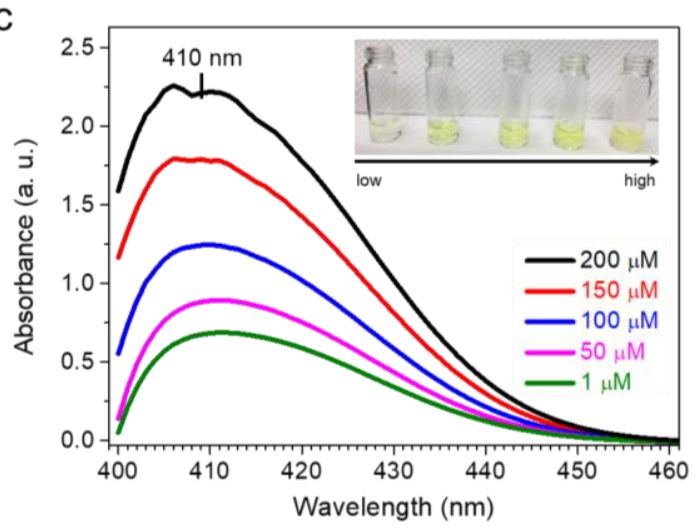

b

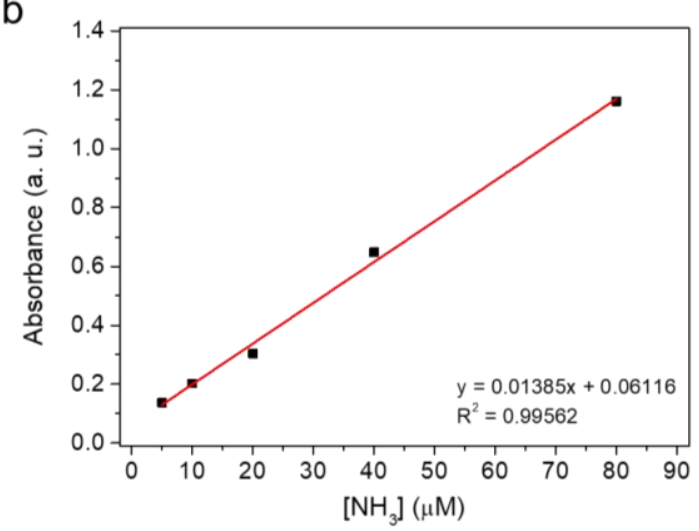

d

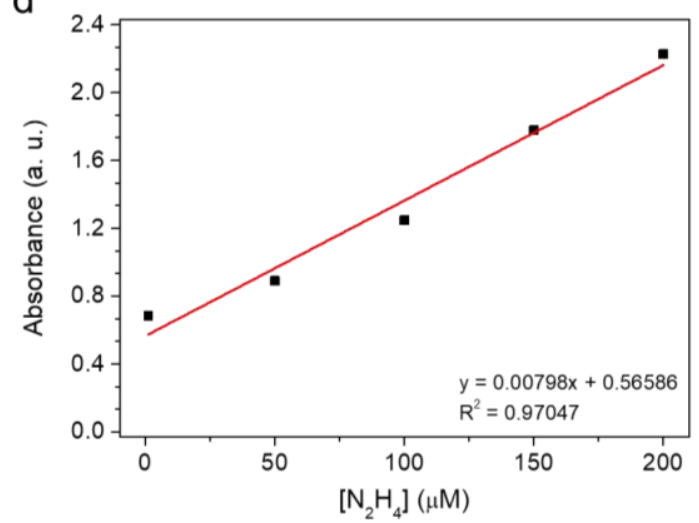

Figure S6. UV-Vis spectra and calibration plots of (a, b) indophenol blue method for $\mathrm{NH}_{3}$ quantification and (c, d) Watt and Chrisp's method for $\mathrm{N}_{2} \mathrm{H}_{4}$ quantification. 
a

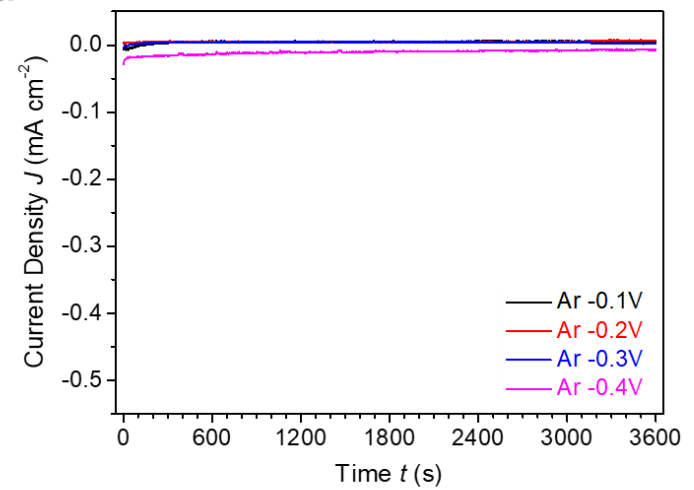

C

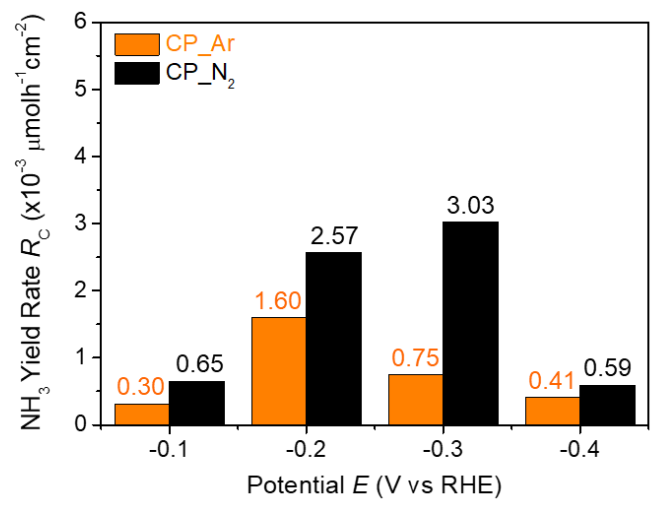

b

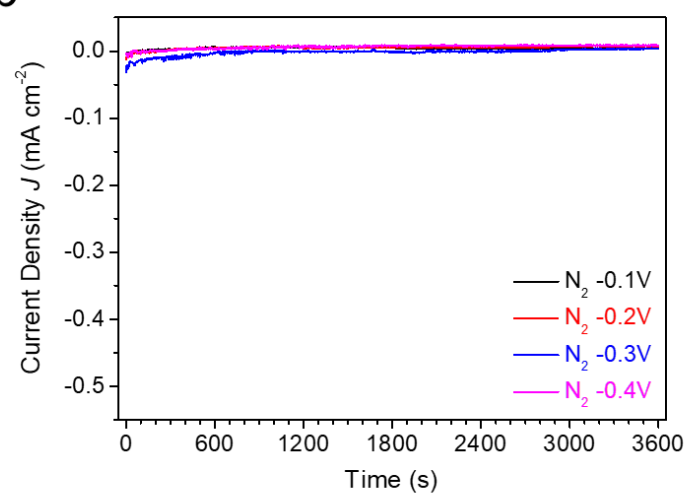

d

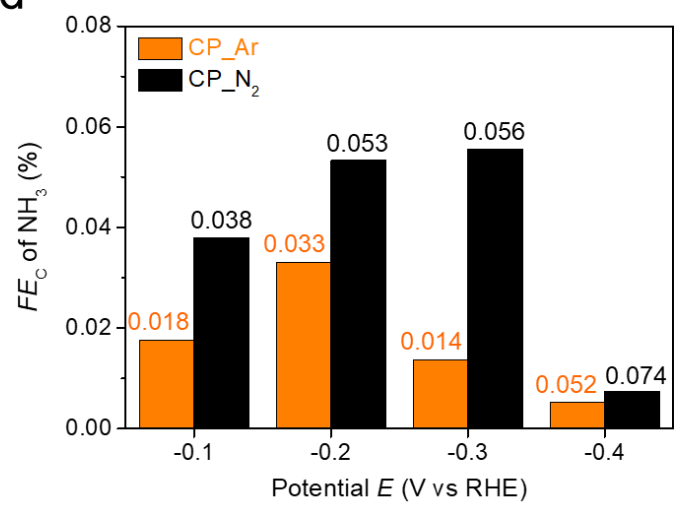

Figure S7. $J$ - $t$ plots of the bare carbon paper operated under (a) $\mathrm{Ar}$ and (b) $\mathrm{N}_{2}$ flow, and their corresponding $E$-dependent distributions in (c) $\mathrm{NH}_{3}$ yield rates and (d) Faradaic efficiencies.
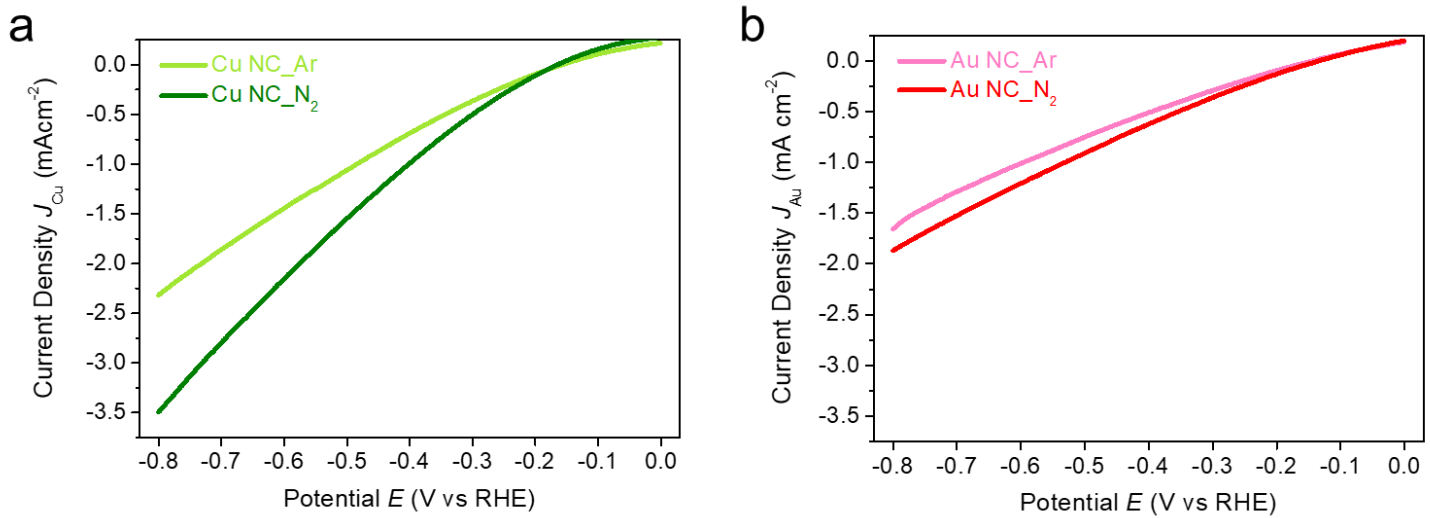

Figure S8. LSV plots of (a) $\mathrm{Cu}$ and (b) Au NC-catalyzed reduction under $\mathrm{Ar}$ and $\mathrm{N}_{2}$ flow at the scan rate of $50 \mathrm{mV} / \mathrm{s}$. 
a

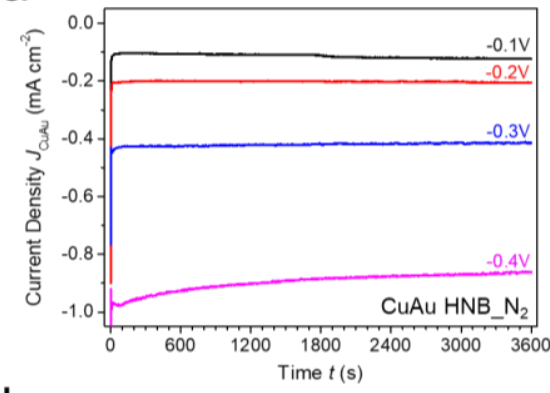

b

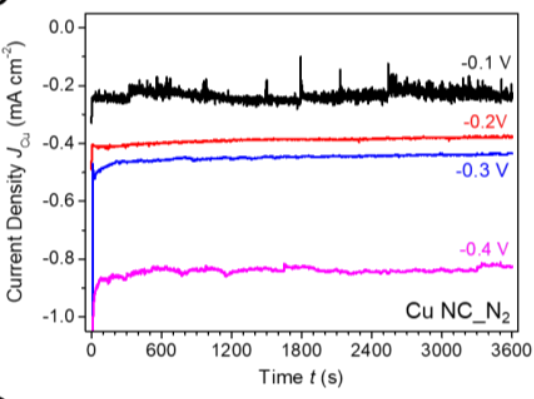

C

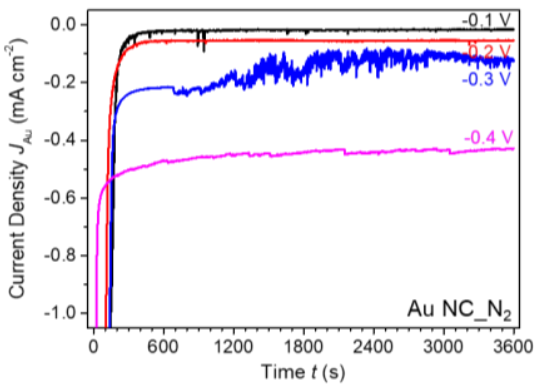

d

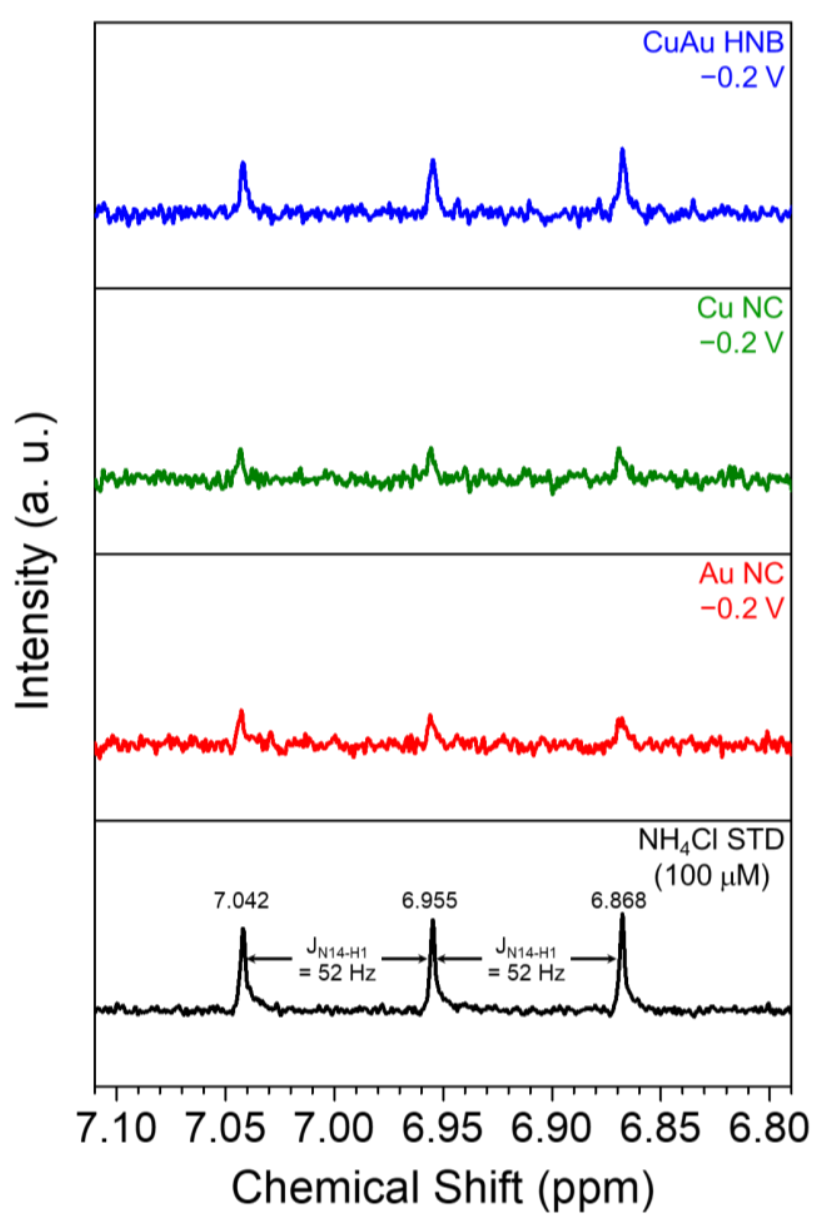

Figure S9. J-t plots of $\mathrm{N}_{2} \mathrm{RR}$ catalyzed by (a) $\mathrm{CuAu} \mathrm{HNBs}$, (b) $\mathrm{Cu} \mathrm{NCs}$, and (c) $\mathrm{Au} \mathrm{NCs}$ at the constant potentials of $-0.1,-0.2,-0.3$, and $-0.4 \mathrm{~V}$ for an hour. (d) ${ }^{1} \mathrm{H}$ NMR spectra of the electrolyte solutions for the catalysts and a standard solution of $100 \mu \mathrm{M} \mathrm{NH} \mathrm{N}_{4} \mathrm{Cl}$. 

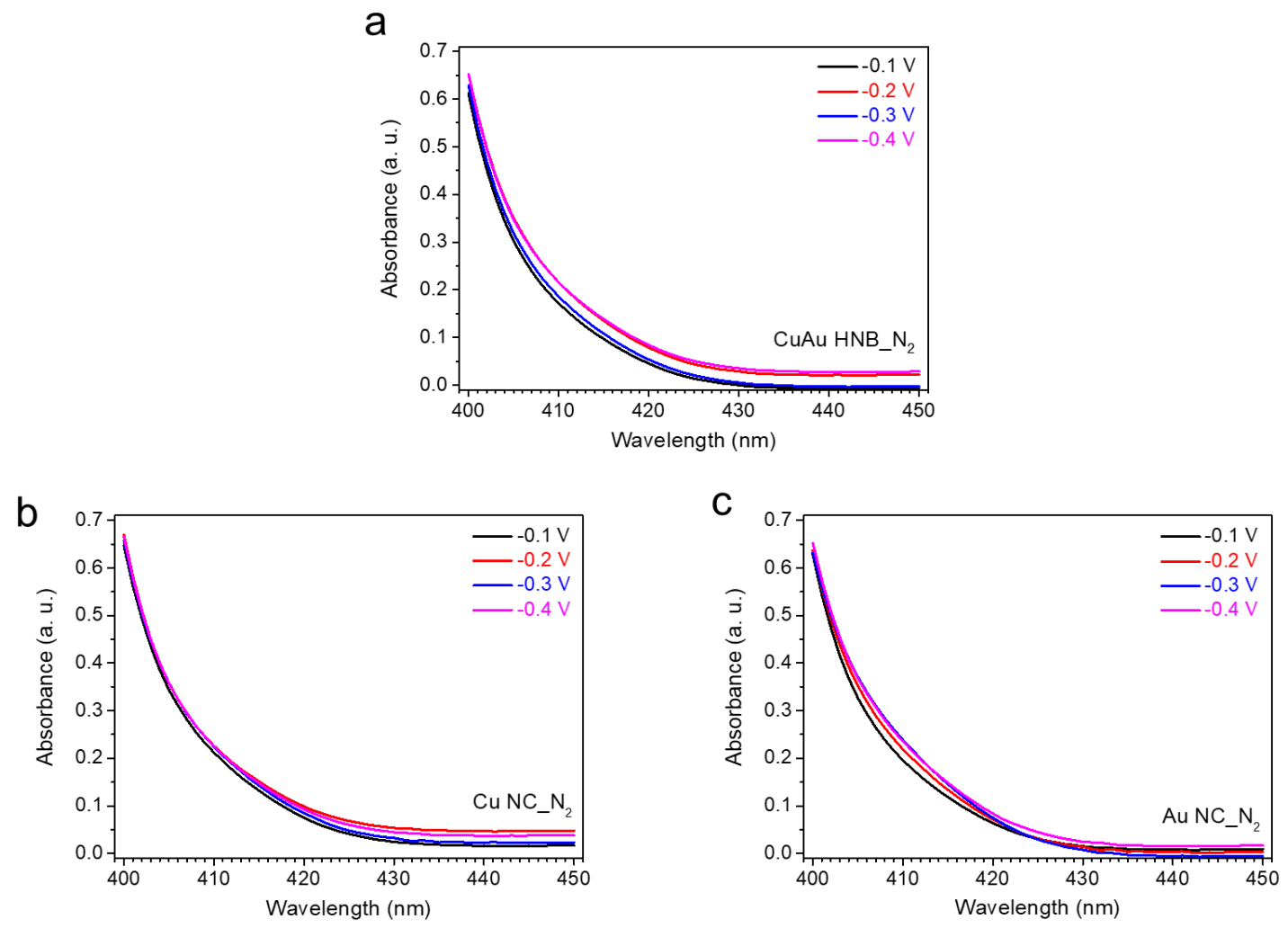

Figure S10. UV-Vis spectra measurements based on the Watt and Chrisp's method show no detectable $\mathrm{N}_{2} \mathrm{H}_{4}$ in the $\mathrm{N}_{2} \mathrm{RR}$ catalyzed by (a) CuAu HNBs, (b) Cu NCs, and (c) $\mathrm{Au}$ NCs. 

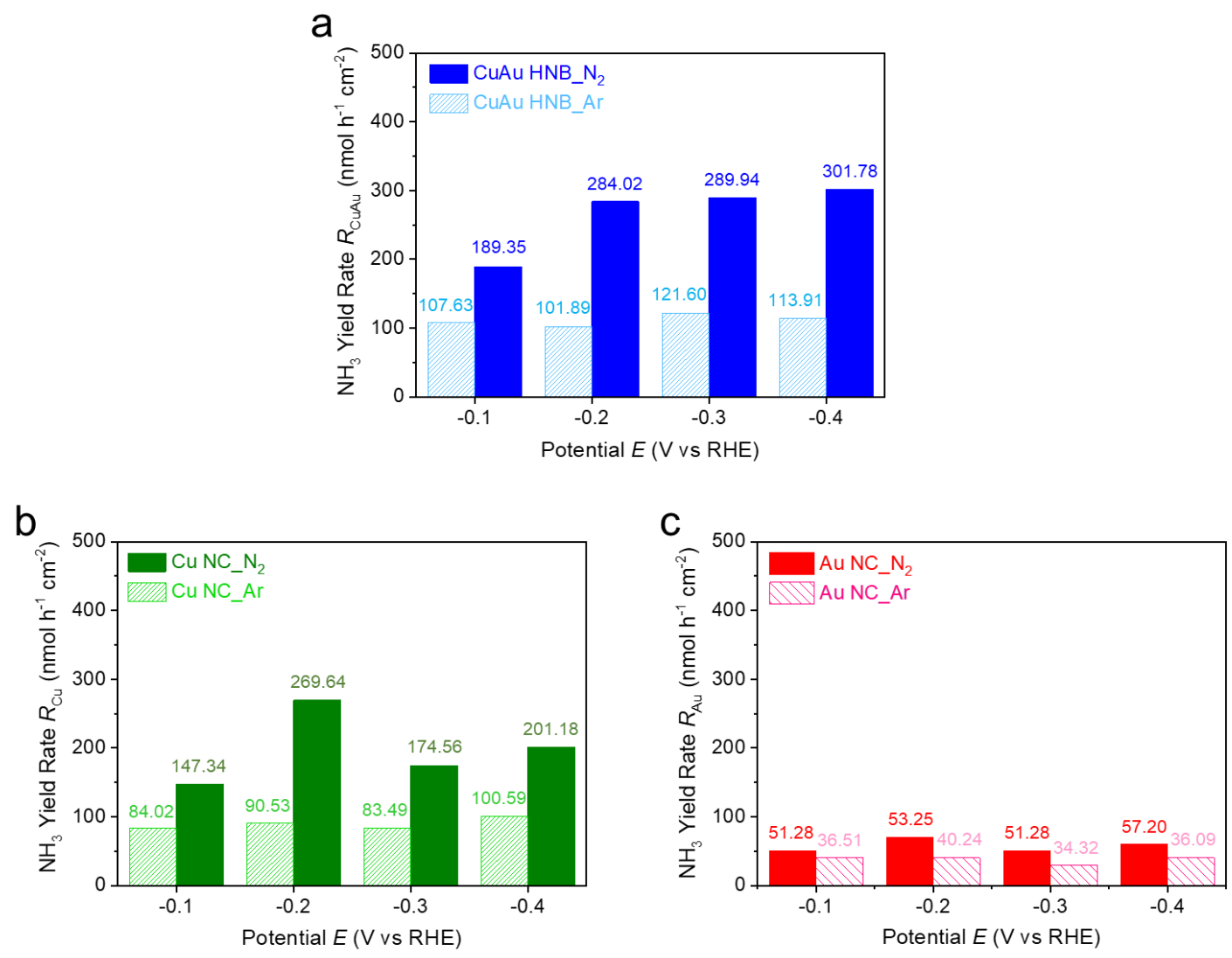

Figure S11. $\mathrm{NH}_{3}$ yield rates of (a) CuAu HNB-, (b) Cu NC-, and (c) Au NC-catalyzed reduction reactions under $\mathrm{Ar}$ and $\mathrm{N}_{2}$ flow. 


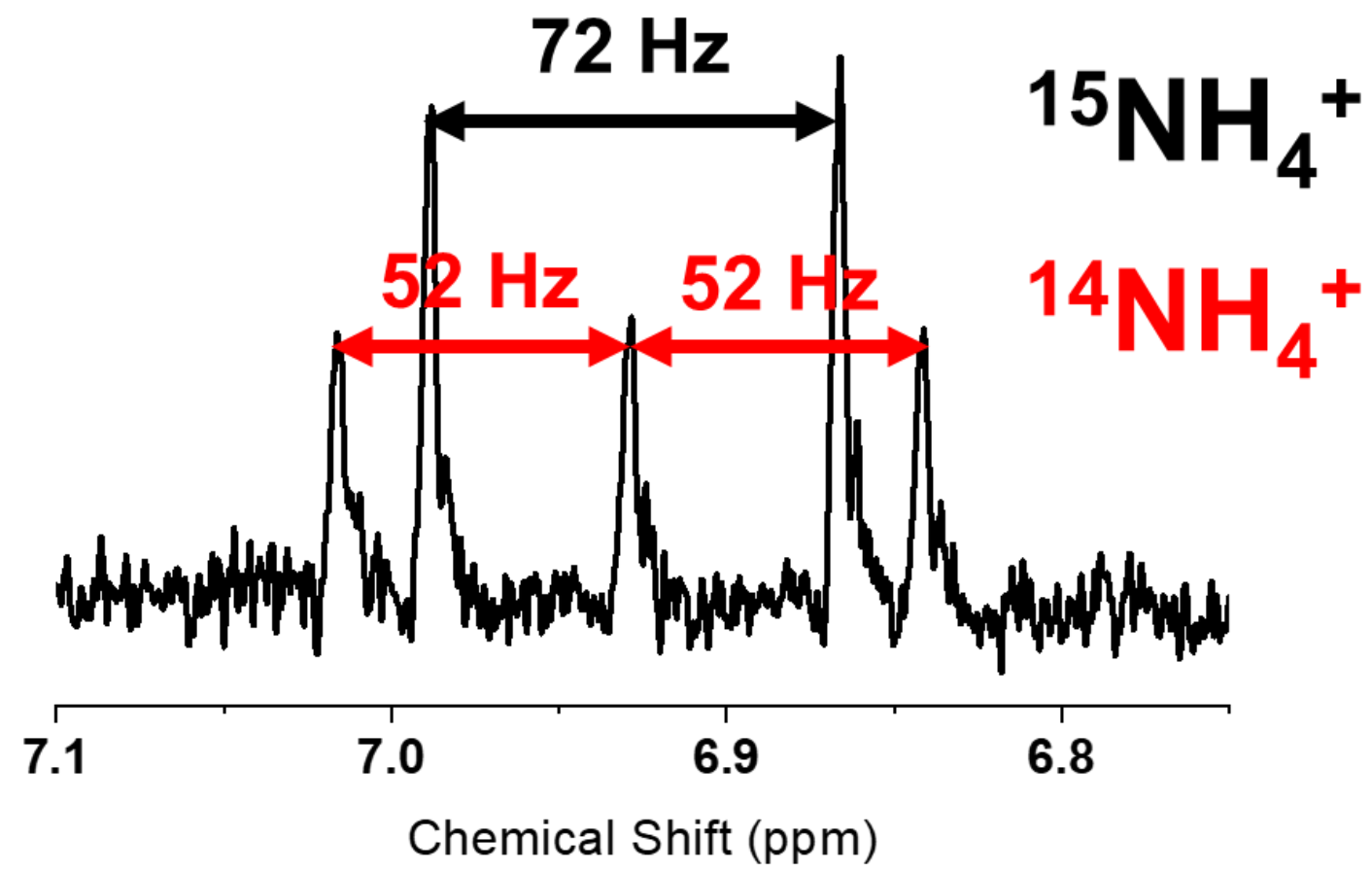

Figure S12. ${ }^{1} \mathrm{H}$ NMR spectrum of the electrolyte solution saturated with ${ }^{15} \mathrm{~N}_{2}$ gas catalyzed by the HNBs. The signals of products contain the triplet peaks with a coupling constant of $52 \mathrm{~Hz}$ from the coupling between ${ }^{1} \mathrm{H}$ and ${ }^{14} \mathrm{~N}$ ( spin 1), and the doublet peaks with a coupling constant of $72 \mathrm{~Hz}$ due to the coupling between ${ }^{1} \mathrm{H}$ and ${ }^{15} \mathrm{~N}$ ( $\operatorname{spin} 1 / 2$ ). 


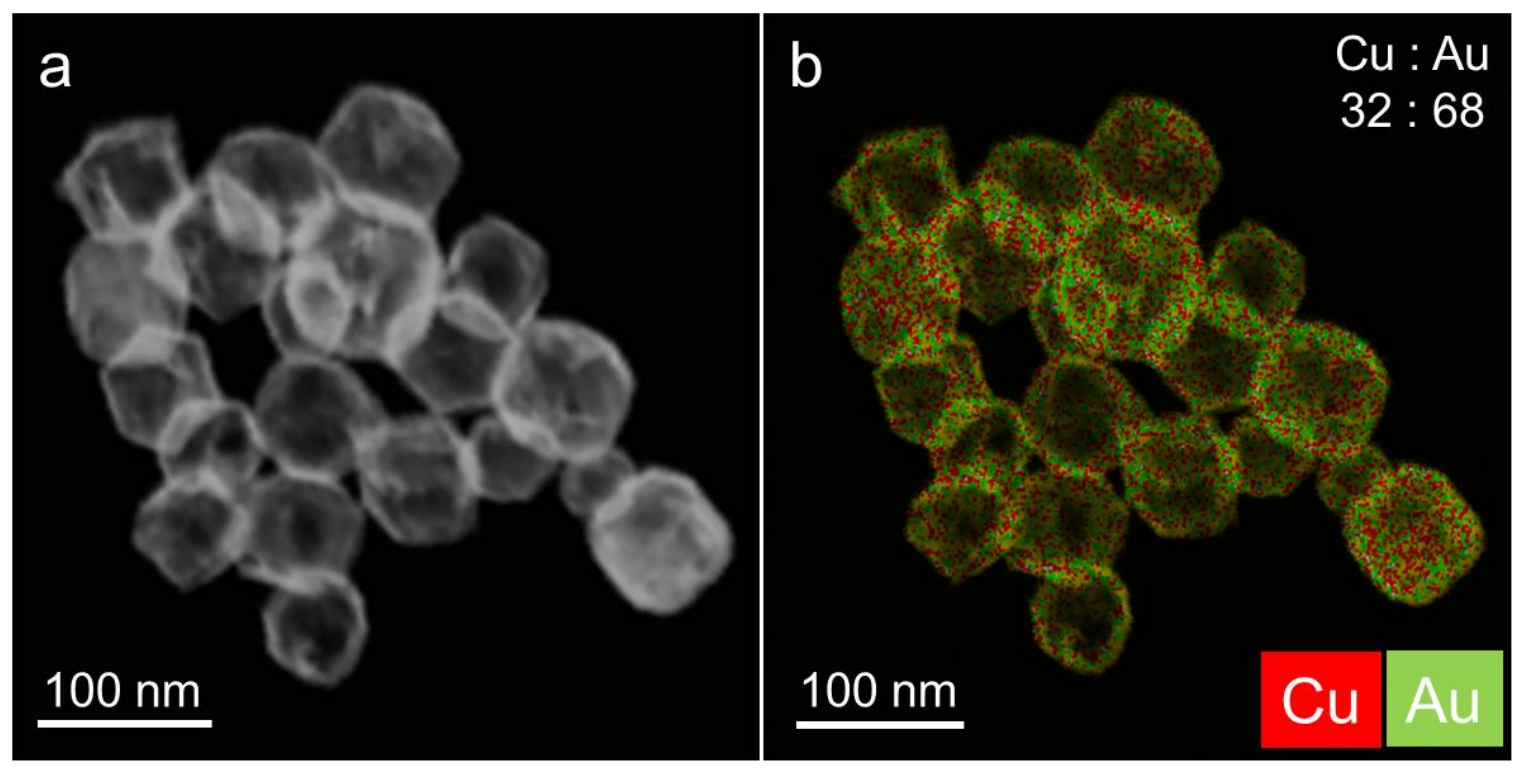

Figure S13. (a) HAADF-STEM image and (b) EDS map of CuAu HNBs after durability test. 


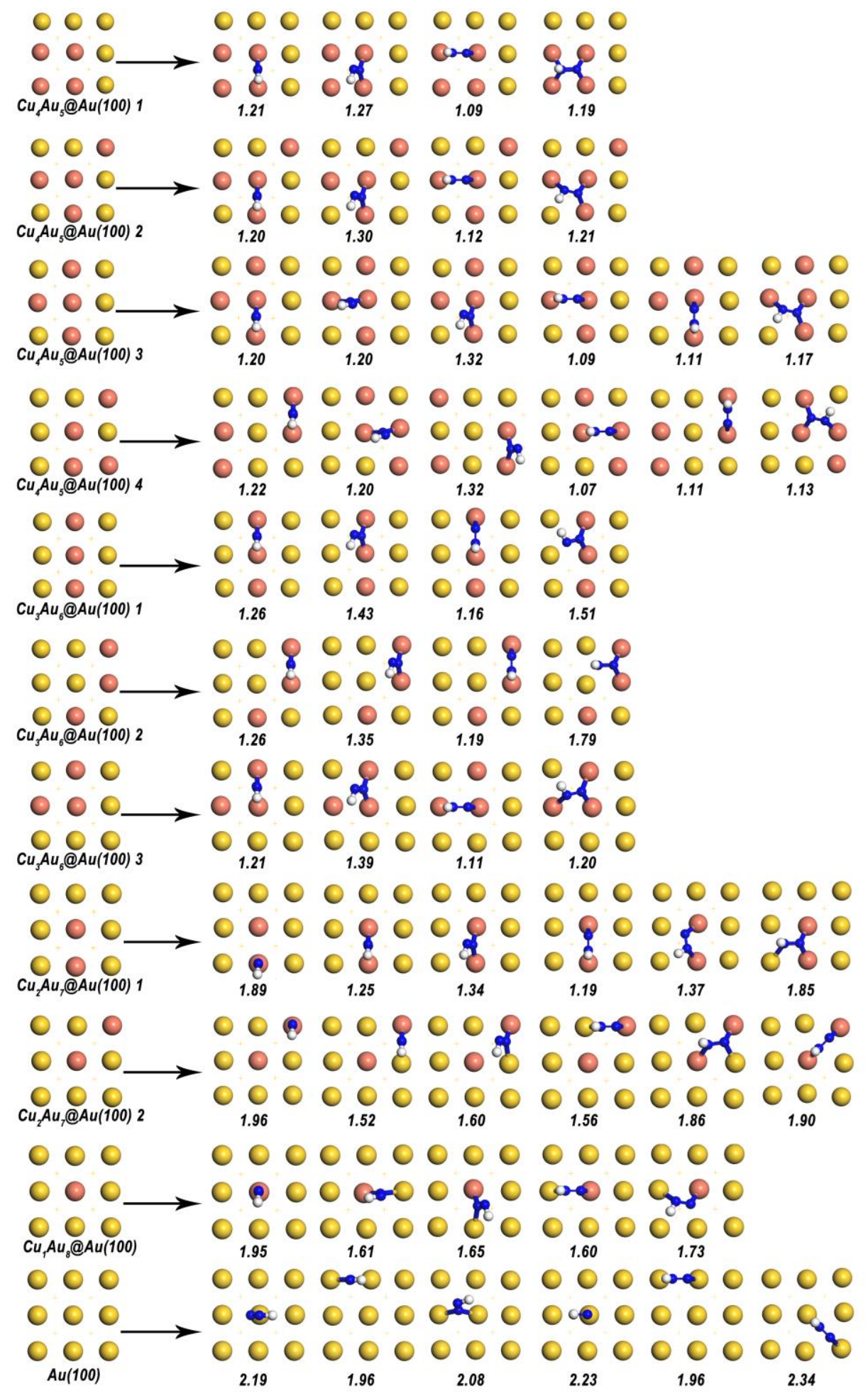

Figure S14. *NNH adsorption configurations considered for $\mathrm{Cu}_{n} \mathrm{Au}_{(9-n)} @ \mathrm{Au}(100)$ with $n$ $=0$ to 4 . 


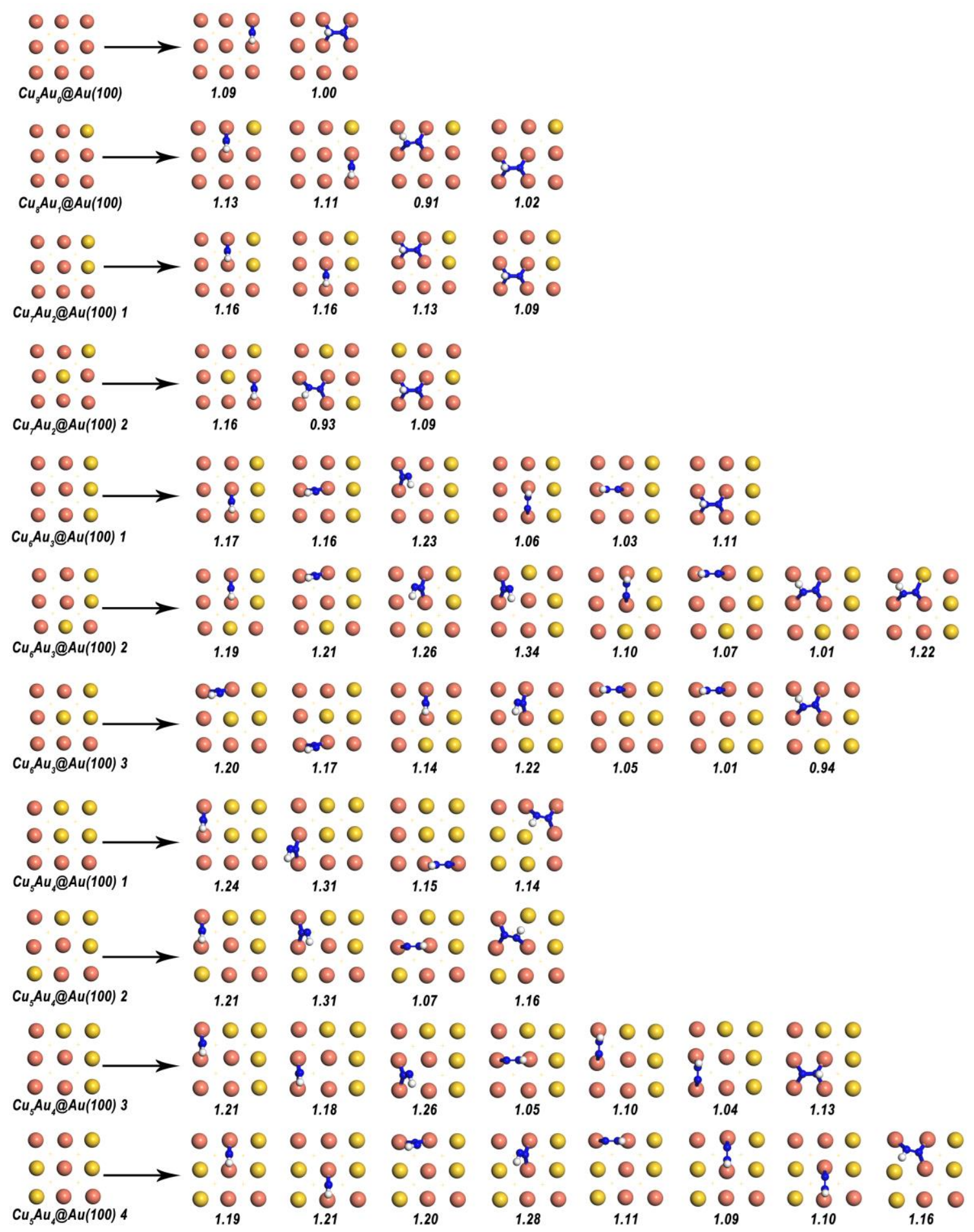

Figure S15. *NNH adsorption configurations considered for $\mathrm{Cu}_{n} \mathrm{Au}_{(9-n)} @ \mathrm{Au}(100)$ with $n$ $=5$ to 9. 


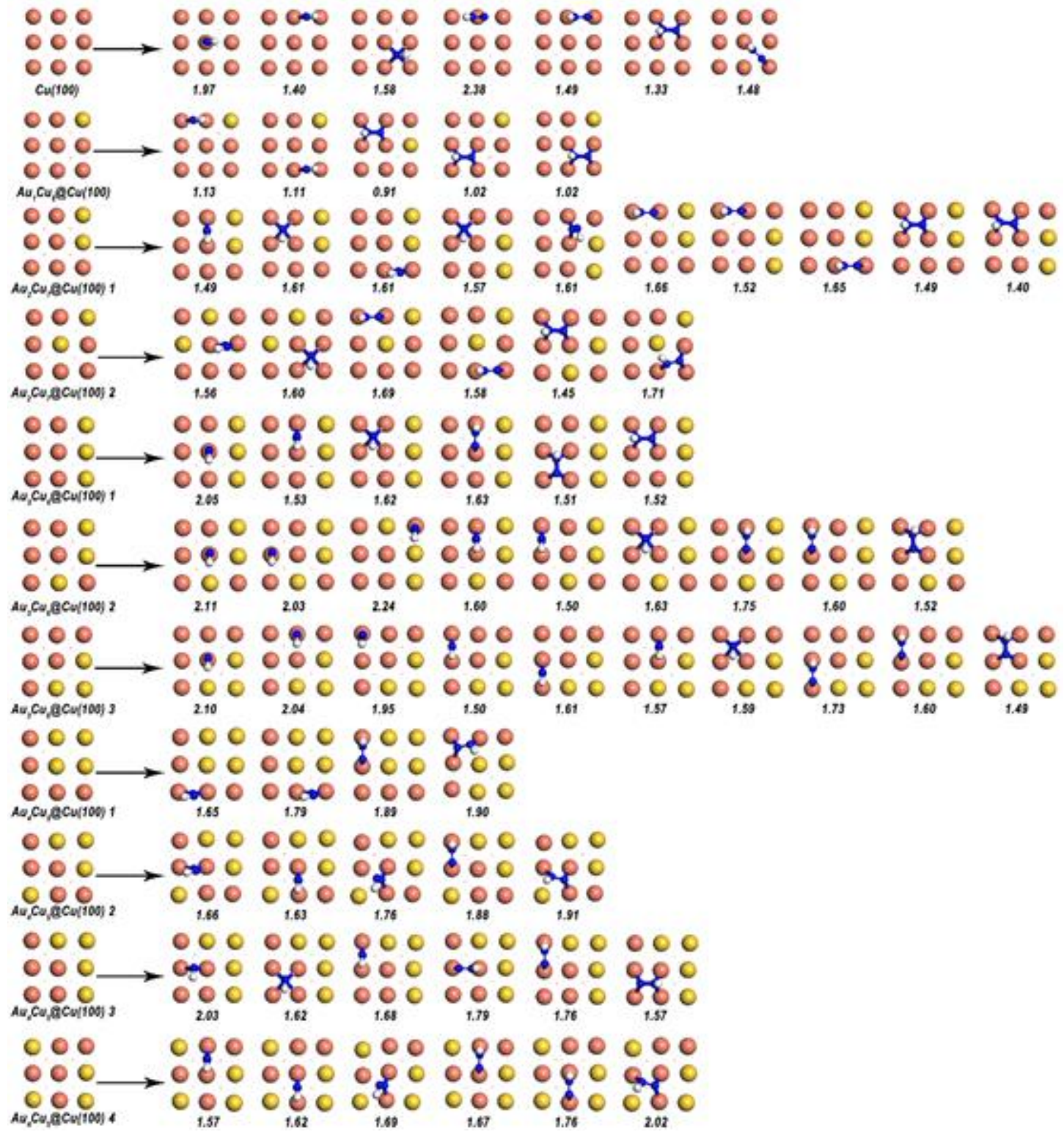

Figure S16. *NNH adsorption configurations considered for $\mathrm{Au}_{n} \mathrm{Cu}_{(9-n)} @ \mathrm{Cu}(100)$ with $n$ $=0$ to 4 . 


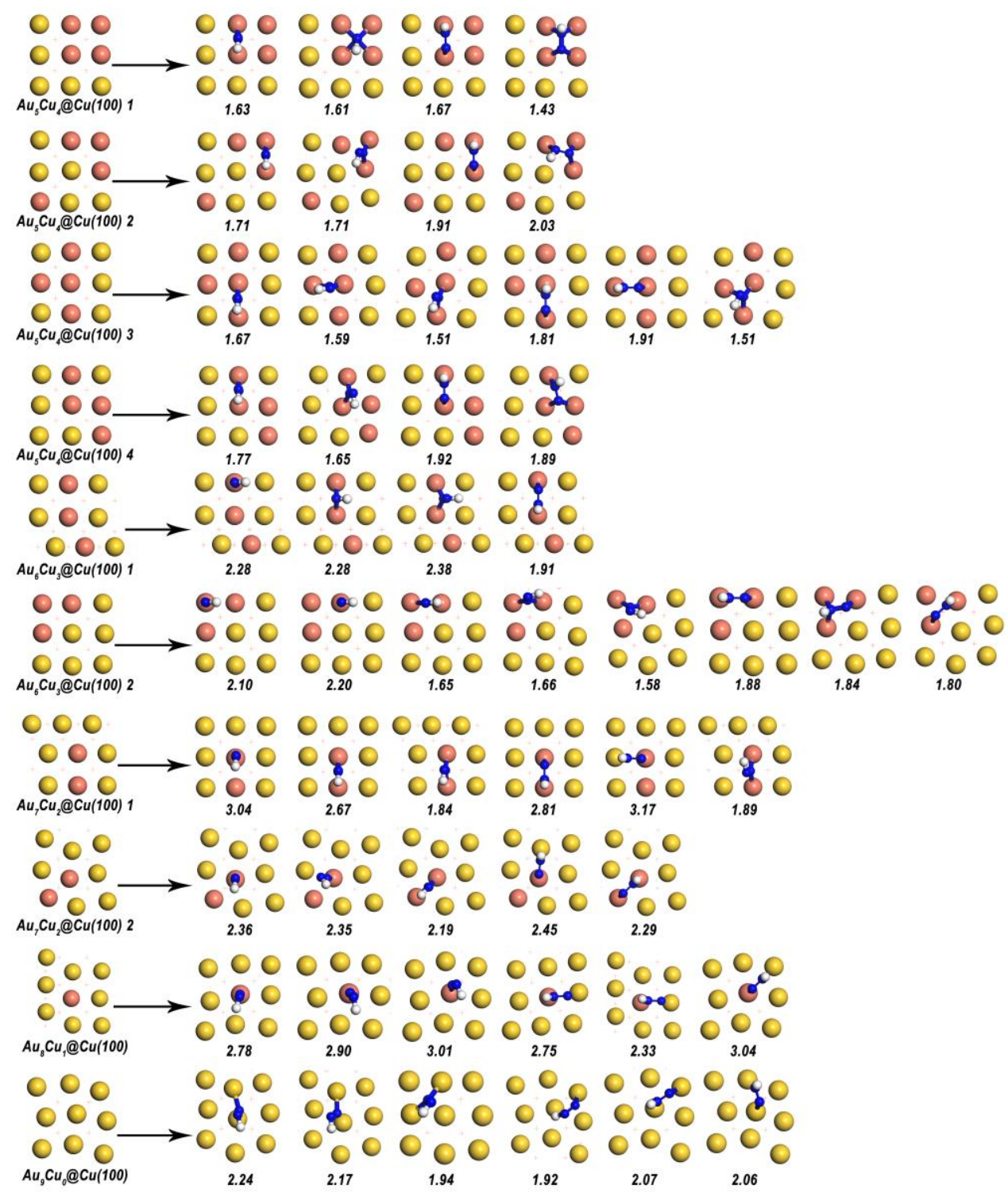

Figure S17. *NNH adsorption configurations considered for $\mathrm{Au}_{n} \mathrm{Cu}_{(9-n)} @ \mathrm{Cu}(100)$ with $n$ $=5$ to 9. 
a

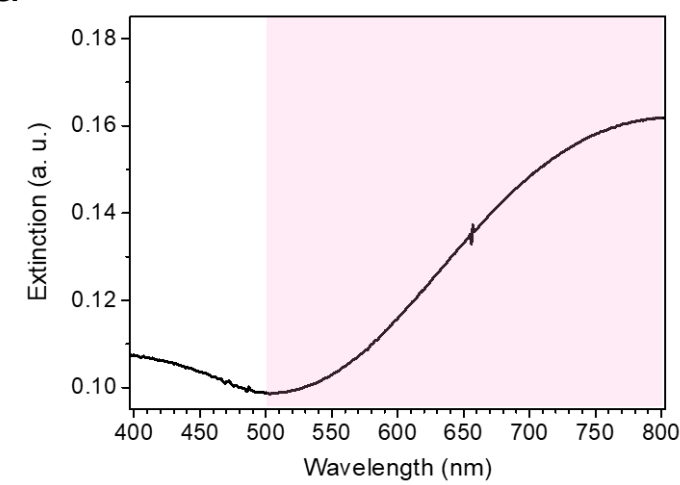

C

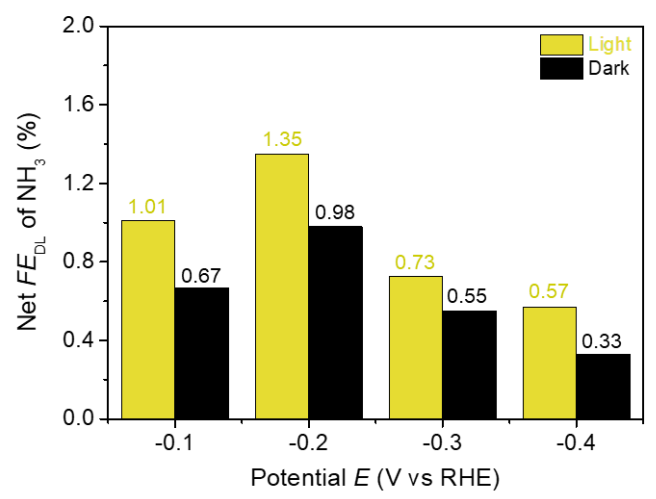

b

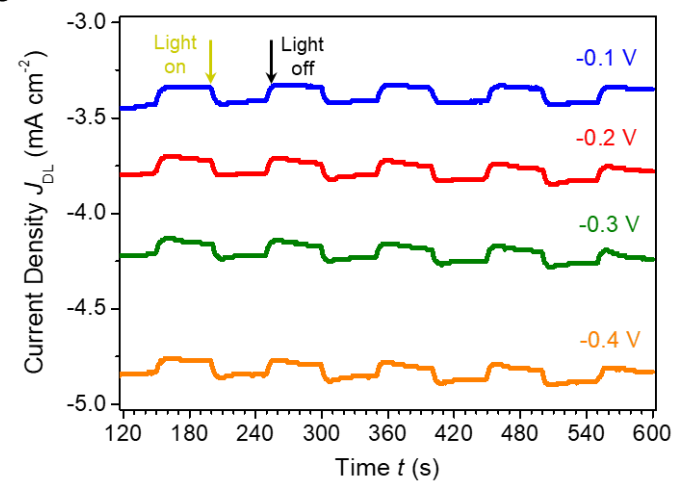

d

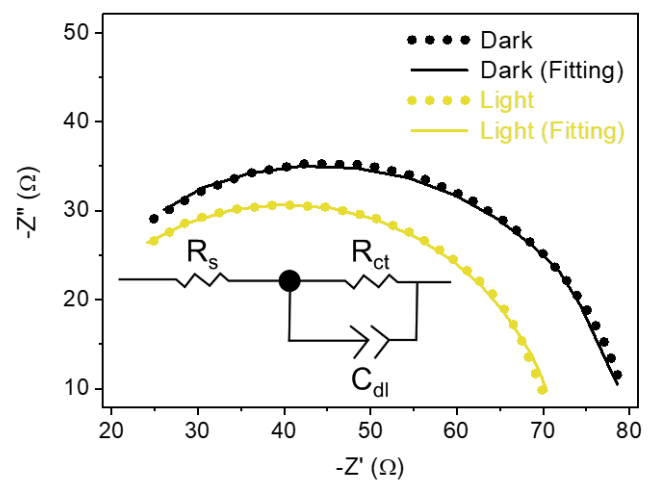

Figure S18. (a) UV-Vis spectra of suspended CuAu HNBs. (b) $J-t$ plot of NRR catalyzed

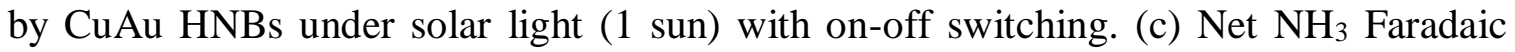
efficiencies in $\mathrm{N}_{2} \mathrm{RR}$ catalyzed by $\mathrm{CuAu} \mathrm{HNBs}$ in dark and under solar light illumination. (d) Nyquist plots for CuAu HNBs in dark and under solar light illumination. 
Table S1. Summary of $\mathrm{N}_{2}$ reduction to $\mathrm{NH}_{3}$ in aqueous solution at ambient conditions

\begin{tabular}{|c|c|c|c|}
\hline Cathode Materials & Electrolyte & FE of $\mathrm{NH}_{3}$ at $E(\mathrm{vs}$ RHE) & References \\
\hline $\mathrm{Li}^{+}$-incorporated PEBCD & $0.5 \mathrm{M} \mathrm{Li}_{2} \mathrm{SO}_{4}$ & $1.71 \%$ at $-0.7 \mathrm{~V}$ & $\begin{array}{l}\text { J. Am. Chem. Soc. } \\
\text { 2017, 139, 9771-9774 }\end{array}$ \\
\hline $\mathrm{Pd}_{0.2} \mathrm{Cu}_{0.8} / \mathrm{RGO}$ & $0.1 \mathrm{M} \mathrm{KOH}$ & $0.6 \%$ at $-0.2 \mathrm{~V}$ & $\begin{array}{l}\text { J. Mater. Chem. A 2018, } 6 \text {, } \\
\text { 17303-17306 }\end{array}$ \\
\hline $\begin{array}{l}\text { spinel } \mathrm{Fe}_{3} \mathrm{O}_{4} \text { nanorods on } \\
\text { Ti mesh }\end{array}$ & $0.1 \mathrm{M} \mathrm{Na}_{2} \mathrm{SO}_{4}$ & $2.6 \%$ at $-0.4 \mathrm{~V}$ & $\begin{array}{l}\text { Nanoscale 2018, } 10, \\
14386-14389 .\end{array}$ \\
\hline $\mathrm{TiO}_{2} / \mathrm{Ti}$ & $0.1 \mathrm{M} \mathrm{Na}_{2} \mathrm{SO}_{4}$ & $2.50 \%$ at $-0.7 \mathrm{~V}$ & $\begin{array}{l}\text { ACS Appl. Mater. Interfaces } \\
\mathbf{2 0 1 8}, 10,28251-28255\end{array}$ \\
\hline $\mathrm{NiO}$ nanodots on graphene & $0.1 \mathrm{M} \mathrm{Na}_{2} \mathrm{SO}_{4}$ & $7.8 \%$ at $-0.7 \mathrm{~V}$ & $\begin{array}{l}\text { ACS Appl. Energy Mater. } \\
\mathbf{2 0 1 9}, 2,2288-2295\end{array}$ \\
\hline $\mathrm{Cr}_{2} \mathrm{O}_{3}-\mathrm{rGO}$ & $0.1 \mathrm{M} \mathrm{HCl}$ & $7.33 \%$ at $-0.6 \mathrm{~V}$ & $\begin{array}{l}\text { Inorg. Chem. 2019, 58, } 2257 \text { - } \\
2260\end{array}$ \\
\hline $\mathrm{Cr}_{0.1} \mathrm{CeO}_{2}$ nanorods & $0.1 \mathrm{M} \mathrm{Na}_{2} \mathrm{SO}_{4}$ & $3.84 \%$ at $-0.7 \mathrm{~V}$ & $\begin{array}{l}\text { Inorg. Chem. 2019, 58, 5423- } \\
5427\end{array}$ \\
\hline $\begin{array}{l}\text { Ultrathin } \mathrm{Ni}_{0.50} \mathrm{Fe}_{0.50} \mathrm{~B} \\
\text { nanosheets }\end{array}$ & $0.1 \mathrm{M} \mathrm{KOH}$ & $3.19 \%$ at $-0.3 \mathrm{~V}$ & $\begin{array}{l}\text { ACS Appl. Energy Mater. } \\
\mathbf{2 0 2 0}, 3,9516-9522\end{array}$ \\
\hline $\begin{array}{l}\mathrm{CoS}_{2} \text { nanoparticles- } \\
\text { embedded N-doped } \\
\text { carbon nanobox derived } \\
\text { from ZIF-67 }\end{array}$ & $0.1 \mathrm{M} \mathrm{HCl}$ & $4.6 \%$ at $-0.15 \mathrm{~V}$ & $\begin{array}{l}\text { ACS Sustainable Chem. Eng. } \\
\mathbf{2 0 2 0}, 8,29-33\end{array}$ \\
\hline $\begin{array}{l}\mathrm{CuAu} \text { nanocage on carbon } \\
\text { paper }\end{array}$ & $0.1 \mathrm{M} \mathrm{KOH}, \mathrm{N}_{2}$ & $7.4 \%$ at $-0.2 \mathrm{~V}$ & This work \\
\hline
\end{tabular}

